\title{
Article \\ Effect of Electric Current on SPS Densification of Spherical Copper Powder
}

\author{
Romaric Collet $^{1}$, Sophie Le Gallet ${ }^{1}$, Frédéric Charlot $^{2}$, Sabine Lay ${ }^{2}$, Jean-Marc Chaix ${ }^{2} \mathbb{D}$ and Frédéric Bernard ${ }^{1, *}$ \\ 1 ICB, UMR 6303 CNRS/Université de Bourgogne Franche-Comté, 9 Avenue Alain Savary-BP 47870, \\ 21078 Dijon, France; rcollet.tsa@hef.fr (R.C.); sophie.le-gallet@u-bourgogne.fr (S.L.G.) \\ 2 SIMAP, UMR 5266 CNRS/Université de Grenoble-Alpes, 1130 Rue de la Piscine-BP 75, \\ 38402 Saint-Martin-d'Hères, France; frederic.charlot@cmtc.grenoble-inp.fr (F.C.); \\ sabine.lay@simap.grenoble-inp.fr (S.L.); jean-marc.chaix@simap.grenoble-inp.fr (J.-M.C.) \\ * Correspondence: fbernard@u-bourgogne.fr
}

check for updates

Citation: Collet, R.; Le Gallet, S.; Charlot, F.; Lay, S.; Chaix, J.-M.; Bernard, F. Effect of Electric Current on SPS Densification of Spherical Copper Powder. J. Manuf. Mater. Process. 2021, 5, 119. https:// doi.org/10.3390/jmmp5040119

Academic Editor: Steven Y. Liang

Received: 3 October 2021

Accepted: 2 November 2021

Published: 5 November 2021

Publisher's Note: MDPI stays neutral with regard to jurisdictional claims in published maps and institutional affiliations.

Copyright: (c) 2021 by the authors. Licensee MDPI, Basel, Switzerland. This article is an open access article distributed under the terms and conditions of the Creative Commons Attribution (CC BY) license (https:// creativecommons.org/licenses/by/ $4.0 /)$.

\begin{abstract}
When a current is involved, as in spark plasma sintering, metallic powders are heated by the Joule effect through both tool and specimen. Other mechanisms might occur, but it is difficult to separate the role of the temperature from the role of the current inside the sample as, in most cases, the two parameters are not controlled independently. In this paper, the consolidation and the densification of a pure copper powder were studied in three configurations for obtaining different electric current paths: (i) current flowing through both the powder and the die, (ii) current forced into the powder and (iii) no current allowed in the powder. Electrical conductivity measurements showed that even low-density samples displayed higher conductivities than graphite by several orders of magnitude. FEM simulations confirmed that these copper specimens were mainly heated by the graphite punches. No modification of the microstructure by the flow of current could be observed. However, the absence of current in the specimen led to a decrease in densification. No significant temperature difference was modeled between the configurations, suggesting that differences are not linked to a thermal cause but rather to a current effect.
\end{abstract}

Keywords: spark plasma sintering; copper powder; electrical conductivity; microstructure

\section{Introduction}

Spark plasma sintering (SPS) shows high performance in sintering metallic powders in a short time. Tokita first suggested that the formation of sparks and plasma enhanced consolidation and densification mechanisms [1], but the lack of evidence for spark discharge and plasma resulted in further research on the mechanisms occurring in SPS devices. Unconventional necks between particles were attributed to local overheating at the contact area [2,3], as well as the occurrence of spark discharges [4,5] or the Branly effect [6]. Ratzker et al. [7] observed that under an electric current, the compressive creep rate of pure copper increased, but there was no evidence that the electric current affected the microstructure or enhanced the reduction of powder surface area [8]. Hulbert et al. [9] concluded, using various in situ techniques, that there was no plasma during the SPS process. The comparison between SPS and conventional sintering processes such as HP (hot pressing) led to conflicting conclusions: differences [10-13] as well as the absence of differences [14-17] between the two processes. However, it seems that specific conditions must be fulfilled in order to show any current effect. Saunders et al. [18] affirmed that the formation of plasma cannot be excluded when higher voltages are employed. In fact, the conditions for plasma formation depend on the electrical and mechanical properties of the materials to be sintered [19]. Most authors agree in considering that the current effects (plasma and/or discharge) are expected to occur between particles that are not in contact [5] or at the beginning of the process when the contact area between particles is very low [20]. Collet et al. [21] observed no specific current effect during the consolidation stage 
of copper powders at $4 \mathrm{MPa}$. In addition, Collard et al. [22] showed that heat conduction made local overheating unrealistic in metallic powders below $100 \mu \mathrm{m}$ in size. Consequently, copper samples could be considered as acting only as a heating element, as in the study by Anselmi-Tamburini et al. where the current distribution in copper parts was modeled [23]. Nevertheless, the material may not exhibit a high value of electrical conductivity, causing the current to flow preferentially through the die and preventing any current effect. Trapp et al. showed that the electrical resistivities of as-received powders (with a thin oxide layer) could be several orders of magnitude higher at lower pressures compared to those of etched powders [24]. The current effect therefore depends on the relative conductivities of the sample and the die and their dependence on temperature. This raises two questions: (i) do copper samples behave as heating elements throughout the SPS process and (ii) does the electric current though the powder affects the consolidation and densification? In order to answer these questions, copper powder will be sintered in three configurations for obtaining three different electric current paths: the standard SPS configuration (St) in which the current flows through both the powder and the die, a second configuration in which the current is forced (FC) into the powder and a third in which no current (NC) is allowed in the powder. The experimentally obtained dependency of the effective conductivity of copper samples on temperature and relative density will be used, together with simple FEM electrical-thermal modeling, in order to analyze and discuss the results.

\section{Materials and Methods}

TEKMAT Cu-38 (Tekna) copper powder prepared by the plasma method was used. This powder consisted of $25 \mu \mathrm{m}$ spherical particles (Figure 1a), with $80 \%$ of particles formed of coarse grains (nearly monocrystalline) and the remainder of small grains (Figure $1 \mathrm{~b}$. The oxygen content was low $(0.041 \mathrm{wt} . \%)$. For this reason, an oxide of only a few nm thickness, described more in detail in [18], covered the particle surface.

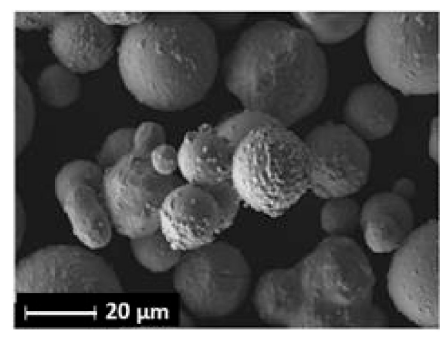

(a)

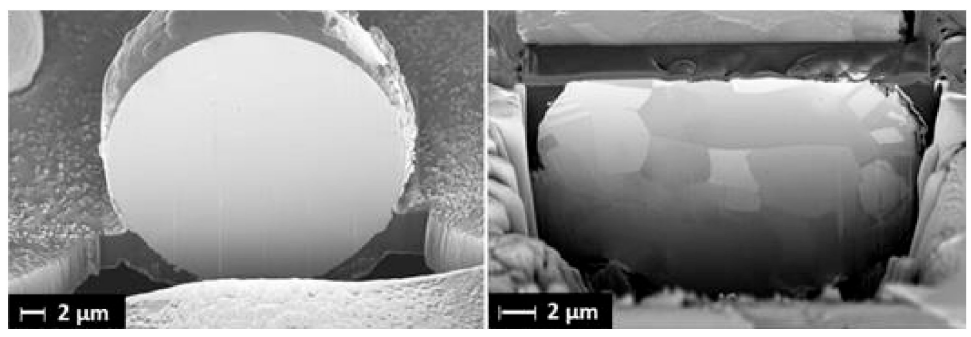

(b)

Figure 1. (a) Morphology (SEM observation) and (b) microstructure (FIB-SEM cross section) of TEKMAT Cu-38 copper powder particles.

The powder (around $17 \mathrm{~g}$ ) was sintered using an HPD 10 device (FCT Systeme, Germany). SPS sintering was performed under vacuum $\left(2 \times 10^{-5}\right.$ bar). For each experiment, the die (with $30 \mathrm{~mm}$ inner diameter) was surrounded by carbon felt in order to limit thermal losses, and a graphite foil was inserted between the powder and the die/punches. Thermal cycles were performed using a constant heating rate $\left(50{ }^{\circ} \mathrm{C} \cdot \mathrm{min}^{-1}\right)$ up to $900^{\circ} \mathrm{C}$, without dwell time, followed by natural cooling. The SPS cycles were interrupted at $500{ }^{\circ} \mathrm{C}$ or $700{ }^{\circ} \mathrm{C}$ to observe the progress of consolidation and densification. A 4 MPa pressure was generally applied during the whole cycle, to ensure electrical contact between the SPS assemblies and to limit the amount of plastic deformation. Two additional experiments were performed with a $28 \mathrm{MPa}$ pressure in order to intensify the effect of pressure. A non-pulsed current with a pattern of 20:0:1:0 (t-on: t-off: n-pulse: t-pause) was used. The displacement of the punches was continuously recorded during the SPS experiments to evaluate the sample shrinkage.

Different set-ups were used for controlling the current path in the die and the sample, in order to analyze the effect of the current (Figure 2). For comparing standard SPS conditions (St) and heating with no current through the powder (NC), the same die and 
punches were used: a graphite (Mersen 2333) die with an outer diameter of $90 \mathrm{~mm}$. The thermocouple was inserted through the die at $2 \mathrm{~mm}$ from the sample. In the case of NC, two alumina platelets with a diameter of $30 \mathrm{~mm}$ and a thickness of $5 \mathrm{~mm}$ were inserted between the punches and the sample, to force the current to pass through the graphite die. For the forced current (FC) case, an isolating alumina die with an outer diameter of $50 \mathrm{~mm}$ was used. The thermocouple was inserted through the punch in order to prevent the alumina die breaking. It was placed in contact with the graphite foil, $0.4 \mathrm{~mm}$ above the sample. To ensure a significant comparison between St and FC configurations, a graphite die (outer diameter of $90 \mathrm{~mm}$ ) with the same thermocouple location was used. The other parameters were kept constant: the same sample diameter (inner die diameter of $30 \mathrm{~mm}$ ), the same die height $(50 \mathrm{~mm})$ and same punch height $(35 \mathrm{~mm})$. The final sample height was typically 3.5 to $5 \mathrm{~mm}$.

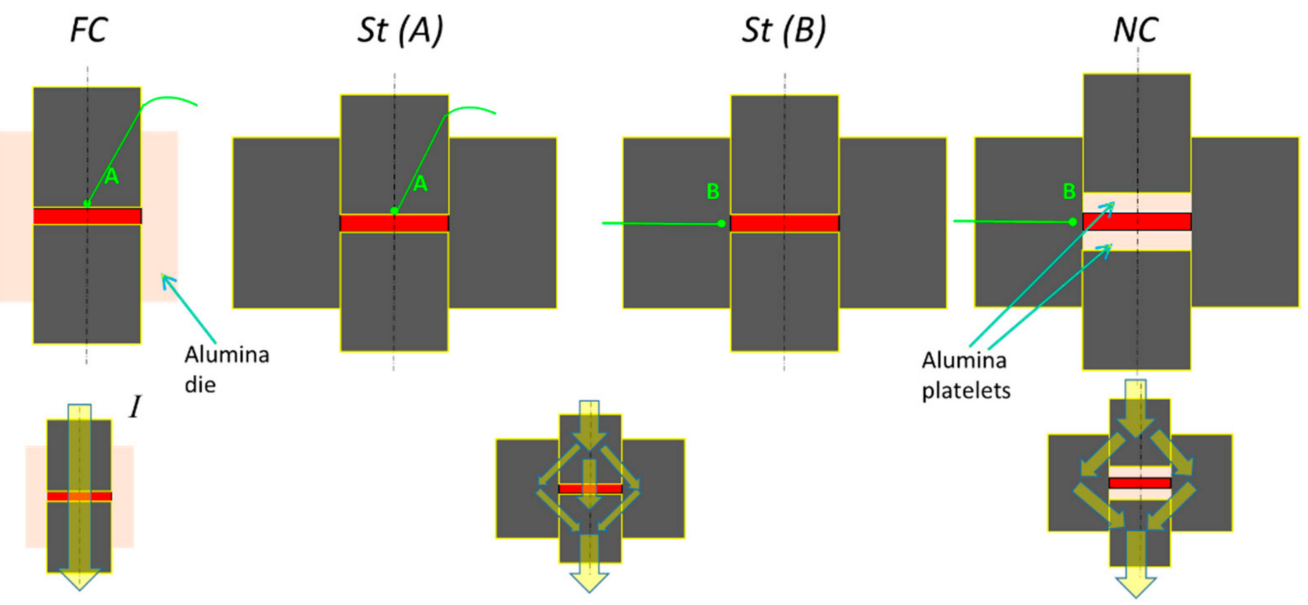

Figure 2. The configurations used to control the current flow. The two standard SPS configurations (St) with graphite die differ in the thermocouple position (A or B), in order to ensure relevant comparisons with the cases of forced current (FC, alumina matrix) or no current (NC, alumina platelets) through the sample.

The sample final densities $\left(d_{\mathrm{f}}\right)$ were evaluated after sintering using the Archimedes method in water and the reference copper density $\left(8.96 \mathrm{~g} \cdot \mathrm{cm}^{-3}\right)$.

The punch displacement was continuously recorded during the experiment and corrected for the device thermal expansion, which was measured by performing an identical cycle with a dense copper sample for each experiment. This enabled calculation of the density evolution using the recorded punch displacement, according to:

$$
d=d_{f} \frac{L_{f}-\Delta L}{L_{f}-\Delta L_{f}},
$$

where $\Delta L$ and $\Delta L_{f}$ are the corrected displacements obtained from the punch displacement at time $t$ and the final time, respectively. The initial density $d_{0}$ was calculated from the same equation with $\Delta L=0$.

Fractured samples were observed with a JEOL 6400F scanning electron microscope (SEM). The electrical conductivities of the sintered samples were measured on the flat surface of the specimens with a SIGMATEST ${ }^{\circledR} 2.069$ apparatus $\left(0.5-65 \mathrm{MS} \cdot \mathrm{m}^{-1}\right.$ probe range) based on electromagnetic measurements (induced current).

\section{Results}

Table 1 summarizes the experimental conditions for the different samples and gives the measured values of the final density and sample height. 
Table 1. Experimental device characteristics and initial and final densities of sample heated up to $900{ }^{\circ} \mathrm{C}$ at constant heating rate $\left(50{ }^{\circ} \mathrm{C} \cdot \mathrm{min}^{-1}\right)$ under pressure $\mathrm{P}$. The initial density $\left(d_{0}\right)$ was calculated from the measured shrinkage at $900{ }^{\circ} \mathrm{C}$, the measured final density $\left(d_{\mathrm{f}}\right)$ and the sample height $(L f)$.

\begin{tabular}{|c|c|c|c|c|c|c|}
\hline Configuration & $\begin{array}{l}\text { Thermocouple } \\
\text { Location }\end{array}$ & $\begin{array}{l}\text { Pressure } \\
P(\mathrm{MPa})\end{array}$ & $\begin{array}{c}\text { Final } \\
\text { Height } \\
L_{f}(\mathrm{~mm})\end{array}$ & $\begin{array}{c}\text { Initial } \\
\text { Density } \\
d_{0}(\%)\end{array}$ & $\begin{array}{c}\text { Final } \\
\text { Density } \\
d_{\mathrm{f}}(\%)\end{array}$ & $\begin{array}{c}\text { Shrinkage } \\
\Delta L / L_{0} \\
(\%)\end{array}$ \\
\hline FC (Alumina die) & Punch (A) & 4 & 4.83 & 60.6 & 76.4 & 20.7 \\
\hline St (Graphite die) & Punch (A) & 4 & 4.90 & 58.2 & 73.6 & 20.8 \\
\hline - St (Graphite die) & Die (B) & 4 & 3.62 & 58.5 & 72.6 & 19.4 \\
\hline $\begin{array}{l}\text { NC (Graphite die + } \\
\text { alumina platelets) }\end{array}$ & Die (B) & 4 & 3.90 & 58.7 & 69.8 & 16 \\
\hline St (Graphite die) & Die (B) & 28 & 3.40 & 63.1 & 97.3 & 35.1 \\
\hline $\begin{array}{l}\text { NC (Graphite die + } \\
\text { alumina platelets) }\end{array}$ & Die (B) & 28 & 3.44 & 63.4 & 96 & 34 \\
\hline
\end{tabular}

The initial densities obtained after a cycle at $4 \mathrm{MPa}$ in the graphite die were close to each other (around 58.5\%). The initial density obtained in the alumina die at the same pressure was higher $(60.6 \%)$. When the pressure was increased to $28 \mathrm{MPa}$, the initial density was approximately $63 \%$.

The presented densification curves were obtained from the measured punch displacements corrected for the device thermal expansion and the final measured specimen density (Archimedes) and dimensions. The device thermal expansion was measured by performing an identical cycle with a dense copper sample for each experiment.

\subsection{Comparison of Standard SPS Conditions with Different Thermocouple Positions (StA and StB)}

Figure 3 compares the densification curves obtained in the graphite die standard configurations (St) for the two thermocouple locations (A and B). The densification curve StB shows some fluctuations at the beginning of the cycle which originate from a temperature regulation problem. A fitted curve (dashed line) is added to facilitate comparison with StA and for use in the following analysis.

The StA curve shows strong densification from low temperatures. This will also be observed later for another configuration. It suggests a higher sample temperature in the set-up, leading to a higher final density for the same measured temperature when starting from the same initial density (Table 1). This illustrates the sensitivity to thermocouple position and justifies the choice of two different St references for FC (which does not allow the position B in the alumina matrix) and for NC (for which the alumina platelets would have distorted the temperature evaluation in position $\mathrm{A}$ ). 


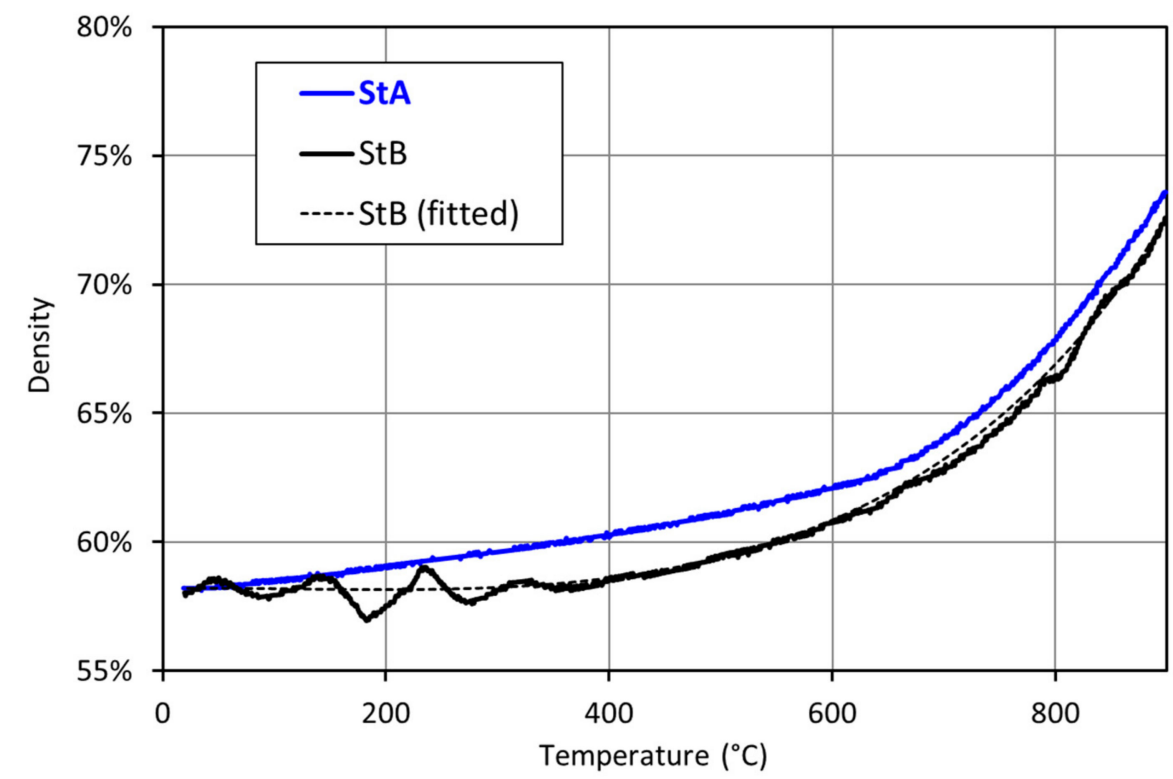

Figure 3. Comparison of standard SPS configurations (St) with two different positions of the thermocouple used to control the thermal cycle (positions A and B in Figure 2).

\subsection{Comparison between Standard SPS (StA) and Forced Current (FC) Conditions}

Figure 4 compares the densification curves obtained in the graphite die (StA) and alumina die (FC) configurations. Some experiments were interrupted at intermediate stages during heating, in order to observe the microstructure evolution on fractured samples (Figure 5).

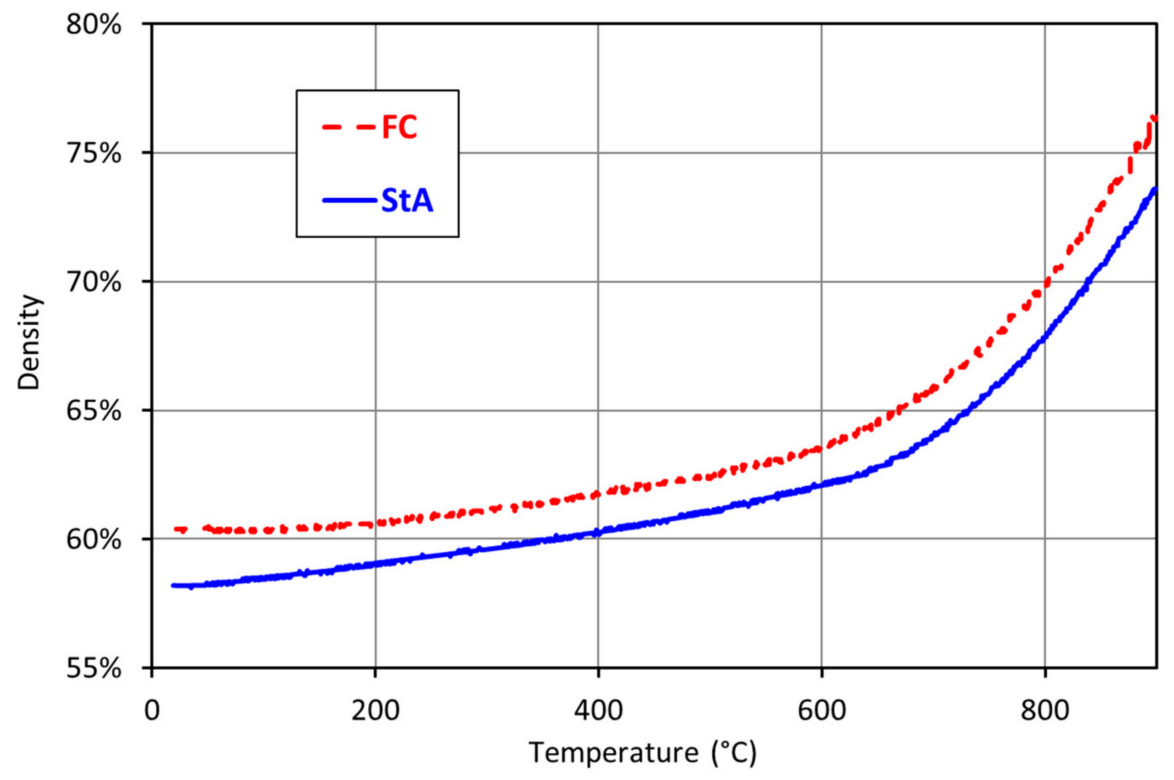

Figure 4. Densification of the copper powder during sintering for standard SPS conditions (St) and forced current (FC) conditions, with applied pressure $4 \mathrm{MPa}$ and heating rate $50{ }^{\circ} \mathrm{C} \cdot \mathrm{min}^{-1}$ (thermocouple in position A). 


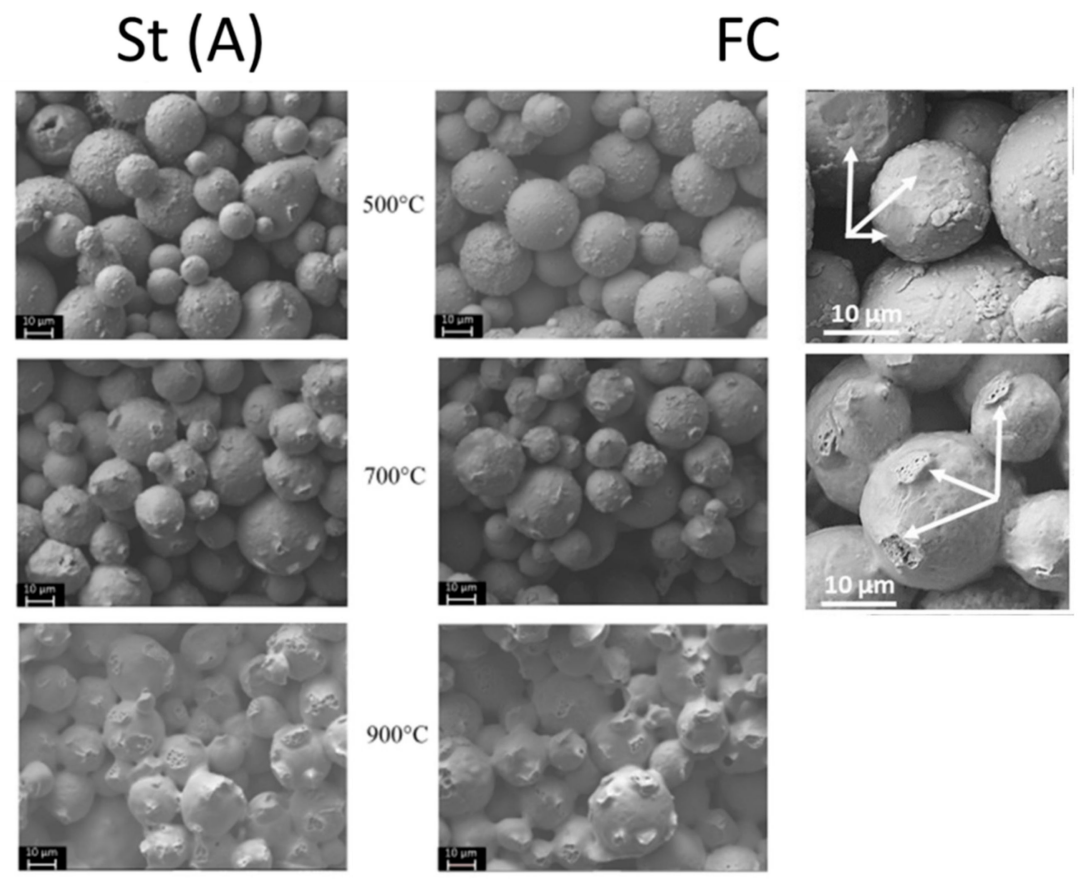

Figure 5. Fracture surfaces observed by SEM on samples after SPS processing in standard (StA) and forced current (FC) conditions, under $4 \mathrm{MPa}$ at $50{ }^{\circ} \mathrm{C} \cdot \mathrm{min}^{-1}$ up to $500^{\circ} \mathrm{C}, 700{ }^{\circ} \mathrm{C}$ and $900{ }^{\circ} \mathrm{C}$.

The densification curves are parallel, with a significant slope from low temperatures which appears to be a "signature" of heating control by the thermocouple in position A. An acceleration can be observed at around $650{ }^{\circ} \mathrm{C}$ in both cases.

The final density (Table 1) was higher after sintering in an alumina die. However, we note that the initial density was also higher after compaction in this die. Consequently, there was no significant effect of the FC configuration with respect to the standard configuration. L. Minier [25] observed a larger discrepancy between the densities of nickel samples sintered in alumina and graphite dies, with densities of 94.5 and $90.4 \%$, respectively. However, nickel is four times less conductive than copper and, unfortunately, the initial densities were not estimated, and the temperature regulation location was different.

SEM observations did not reveal any differences between the two configurations. The fractographs at $500{ }^{\circ} \mathrm{C}$ showed that there were no (or very few) dimples on the particle surface. Their absence indicates that neck formation and diffusion bonding has not yet taken place. Flattened areas at the contacts were observed (indicated by white arrows in the enlarged picture in Figure 5). The fractography at $700{ }^{\circ} \mathrm{C}$ show that small areas with dimples appeared, confirming the development of necks between particles. Some areas with dimples are indicated by white arrows in the enlarged picture in Figure 5 . At $900{ }^{\circ} \mathrm{C}$, the areas with dimples have increased in size, due to neck growth.

\subsection{Comparison of Standard SPS (StB) and No Current (NC) Conditions}

Figure 6 compares the densification curves obtained in graphite dies in the configurations with alumina platelets $(\mathrm{NC})$ and without $(\mathrm{StB})$. The fractured samples were observed and showed the same characteristics as those in Section 3.2., i.e., flattened contacts without bonding at $500{ }^{\circ} \mathrm{C}$ and diffusion bonding and increasing dimples above $700{ }^{\circ} \mathrm{C}$. They are not reported here. 


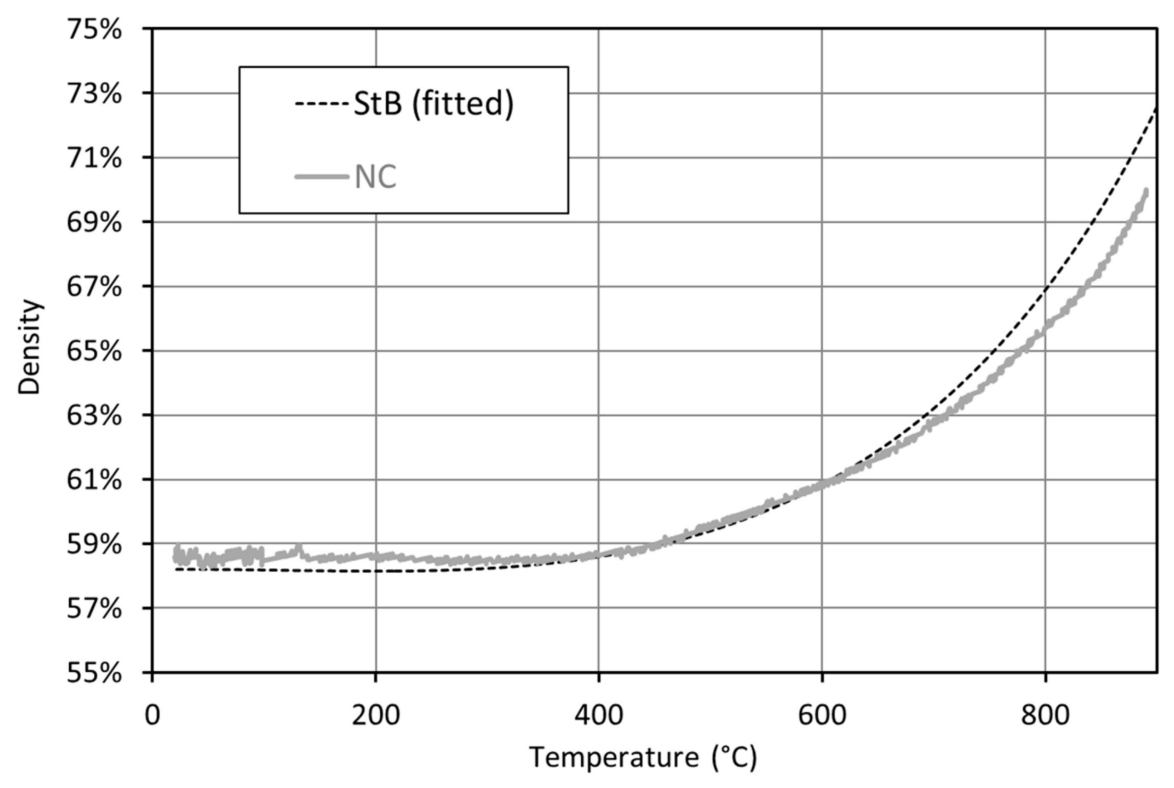

Figure 6. Densification of the copper powder during sintering in the cases of no current (NC) and standard SPS (StB), with applied pressure $4 \mathrm{MPa}$, heating rate $50{ }^{\circ} \mathrm{C} \cdot \mathrm{min}^{-1}$ (thermocouple in position B).

Almost no densification was observed below $400{ }^{\circ} \mathrm{C}$. The densification curves diverge above $600{ }^{\circ} \mathrm{C}$, leading to a lower density for the NC configuration.

To enhance the difference between the two configurations, the pressure was increased in order to favor the contact areas at low temperature and, consequently, the current flow through the sample.

The densification curves under a pressure of $28 \mathrm{MPa}$, as well as the fractography at different temperatures, are shown in Figure 7.
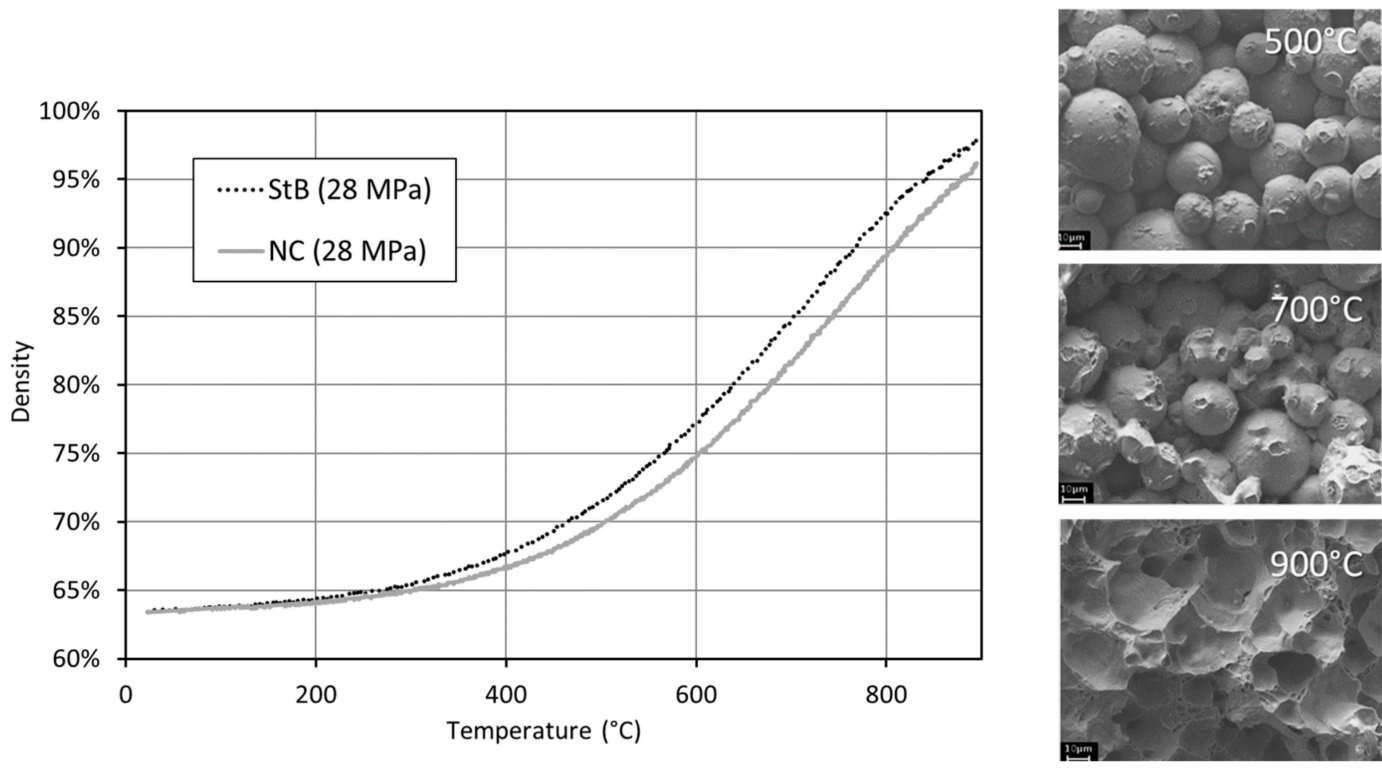

Figure 7. Densification of the copper powder during sintering in the cases of no current (NC) and standard SPS (StB) when a pressure of $28 \mathrm{MPa}$ is applied. Fracture surfaces observed by SEM in the sample obtained in standard conditions (StB) at 500,700 and $900{ }^{\circ} \mathrm{C}$.

As expected, under $28 \mathrm{MPa}$ pressure, densification began earlier than under $4 \mathrm{MPa}$, with the higher pressure leading to an increased plastic deformation. The St and NC 
curves diverge earlier (from $300^{\circ} \mathrm{C}$ ). The highest final densification still occurred in the standard configuration.

Both samples were almost dense at $900{ }^{\circ} \mathrm{C}$, but the final density was slightly higher in the standard configuration $(97.3 \pm 0.5 \%)$ than in the no current configuration $(96.0 \pm 0.2 \%)$ At $28 \mathrm{MPa}$, the necks formed earlier compared to the experiments at $4 \mathrm{MPa}$, but there is no visible microstructural difference between NC and St configurations; hence, only the fractographs of the sample obtained for NC are presented Figure 7.

\section{Discussion}

No significant difference could be observed between FC and St configurations, but a small systematic difference between St and NC configurations was observed. Differences linked to the position of the thermocouples were also noted, i.e., faster densification before $600{ }^{\circ} \mathrm{C}$ for the thermocouple in position A (located in the punch).

Furthermore, some evaluations of heating by simulation were performed, using electrical conductivity data measured in our materials.

\subsection{Electrical Conductivity throughout the SPS Process}

The electrical conductivity of a sample depends on its purity, density and temperature, but also on its thermal history. Compressibility tests, performed in an $8 \mathrm{~mm}$ tungsten die, showed that the relative densities of copper compacts varied between $55.5 \%$ when compacted under $2 \mathrm{MPa}$ to $60 \%$ under $20 \mathrm{MPa}$. Even in the case of the $60 \%$ dense compacts, the electrical conductivity was too low to be measured with the SIGMATEST ${ }^{\circledR} 2.069$ probe $\left(<0.5 \mathrm{MS} \cdot \mathrm{m}^{-1}\right)$. The diffusion bonds between particles were not yet formed and the native oxide layer on the copper particles acted as conductivity barrier, so that high electrical contact resistance existed between the particles. For this reason, the correlation between electrical conductivity and density was investigated via electrical conductivity measurements at room temperature on samples sintered at different temperatures in the SPS device (Figure 8), in order to estimate the conductivity of samples during the sintering process after the very first step, where grain-to-grain contacts are formed.

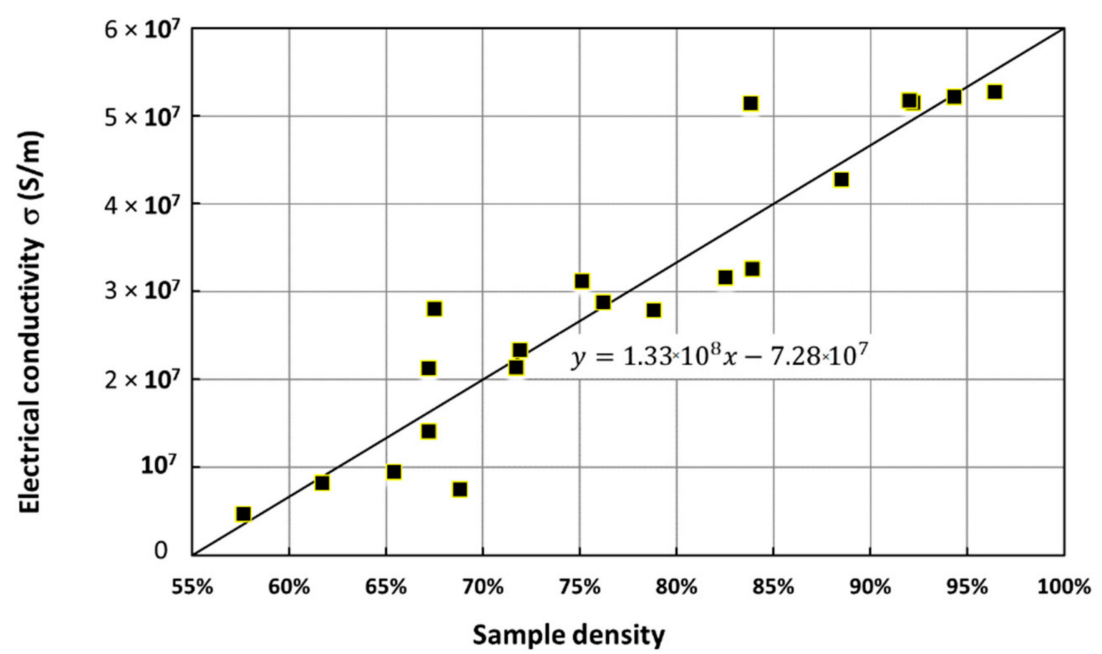

Figure 8. Effective electrical conductivity at room temperature of $\mathrm{Cu}$ samples sintered by SPS at temperatures between 300 and $1000{ }^{\circ} \mathrm{C}$.

The linear regression shows that the effective electrical conductivity at room temperature $(\sigma)$ can be expressed as a function of the sample relative density $d$ :

$$
\sigma_{\mathrm{T}_{0}}=1.33 \times 10^{8} \times(d-0.55),
$$


This simple linear relationship, which is similar to the well-known Bruggeman effective medium formula [26] with a realistic percolation threshold of $55 \%$ instead of $1 / 3$, is in better agreement with experimental results than previous experimentally based relations such as that of Argento [27]:

$$
\sigma^{*}=\sigma\left(\frac{d-d_{0}}{1-d_{0}}\right)^{\frac{3}{2}\left(1-d_{0}\right)}
$$

The effective conductivity becomes zero when the density is 55\%, which roughly corresponds to the natural packing density of the powder, and it reaches $60 \times 10^{6} \mathrm{~S} / \mathrm{m}$ for dense copper, which is a classic typical value for $\mathrm{Cu}$. It must be kept in mind that (2) was obtained for sintered samples, while cold-compacted samples exhibited very low conductivity even at $60 \%$ density. Note that from $58 \%$ density, the partially sintered samples had a conductivity of the order of $5 \times 10^{6} \mathrm{~S} / \mathrm{m}$, while that of graphite is of the order of $6.3 \times 10^{4} \mathrm{~S} / \mathrm{m}$, i.e., 70 to 80 times lower.

During sintering, the electrical conductivity of the sample $\left(\sigma_{T}\right)$ also varies with temperature $T$, due to the intrinsic temperature dependency of bulk conductivity:

$$
\sigma_{T}=\sigma_{T_{0}} \frac{1}{1+\alpha\left(T-T_{0}\right)}
$$

where $\sigma_{T 0}$ is the electrical conductivity at room temperature (calculated using (2)) and $\alpha$ is the temperature coefficient of resistivity $\left(\alpha=0.00393{ }^{\circ} \mathrm{C}^{-1}\right.$ in copper [28]).

The evolution of the effective electrical conductivity of the sample $\left(\sigma_{\mathrm{T}}\right)$ throughout a typical SPS experiment at constant heating rate is shown in Figure 9. The density was calculated from the punch displacement, continuously recorded during the SPS cycle. It evolved from 58 to $72 \%$ between room temperature $\left(T_{0}=20{ }^{\circ} \mathrm{C}\right)$ and $900{ }^{\circ} \mathrm{C}$ at $4 \mathrm{MPa}$. The sample conductivity was deduced from (2) and (4). The electrical conductivity of the graphite die is plotted for comparison. It was calculated from (3) with $\sigma=62,500 \mathrm{~S} \cdot \mathrm{m}^{-1}$ at room temperature (Mersen data) and $\alpha=-0.0005{ }^{\circ} \mathrm{C}^{-1}$ [28].

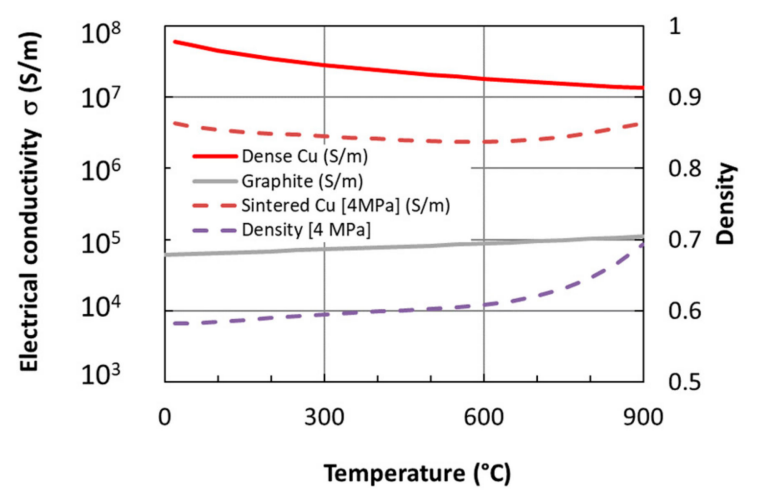

(a)

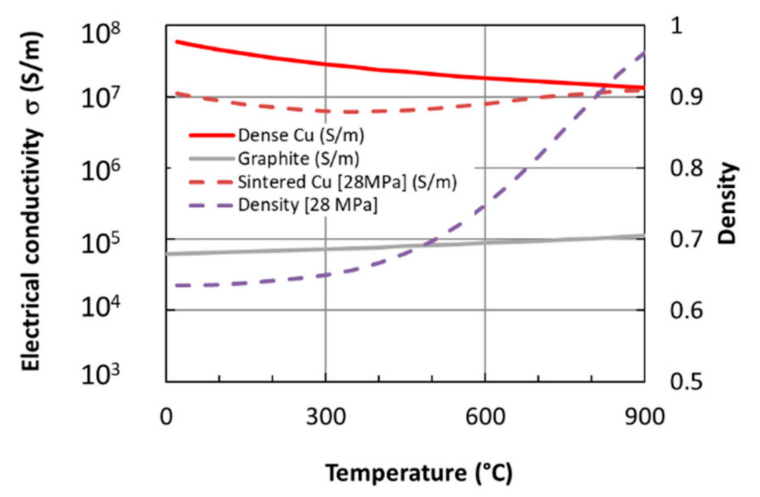

(b)

Figure 9. Evolution of the relative density of a copper sample during SPS experiments at constant heating rate $\left(\mathrm{d} T / \mathrm{d} t=50^{\circ} \mathrm{C} \cdot \mathrm{min}^{-1}\right)$ and effective electrical conductivity of the copper sample calculated from the density and Equations (2) and (3), for two applied pressures: (a) $p=4 \mathrm{MPa}$ and (b) $p=28 \mathrm{MPa}$. The conductivities of graphite and dense copper are plotted for comparison purposes.

The shape of the conductivity curve, with a minimum value (for sintered $\mathrm{Cu}$ ), results from two opposite and competitive effects when the temperature is increased: the increase in particle contacts due to sintering (2) and the decrease in the bulk conductivity (4):

- From room temperature to around $450{ }^{\circ} \mathrm{C}$, the sample conductivity decreases because the bulk conductivity decrease overrides the slow sintering processes. This estimation assumes that good conductivity contacts are formed, which is required for applying 
(2). At the very beginning of the SPS process, the powder conductivity is much lower, due to the abovementioned point;

- $\quad$ Above $450{ }^{\circ} \mathrm{C}$, the strong densification while the temperature is increasing leads to an increase in the effective electrical conductivity.

As soon as good conductive contacts between particles were formed, the effective conductivity of the copper sample became more than 25 times higher than that of the graphite tool. As the diameter ratio between the sample and the die was 3 (90 and $30 \mathrm{~mm}$, respectively) i.e., the surface ratio was 8 , the specific resistance of the powder sample opposing the current flow was typically $1 / 3$ of that of the die, so that a significant total current was flowing in the powder and in the die.

\subsection{FEM Simulations of the Different Configurations}

FEM simulations were used to compare the characteristic behaviors of the St, FC and NC configurations, using simplified conditions representative of experiments. In each case, a predefined voltage was applied, with a value adapted to ensure a roughly constant sample heating rate close to $50^{\circ} \mathrm{C} / \mathrm{min}$. The thermal boundary conditions were: (i) the thermally insulated ends of the (long) punches and (ii) the radiative loss to the environment from the other outer surfaces (emissivity set to 1). These oversimplified conditions were not intended to simulate complex actual experiments, but to provide general tendencies. Calculations were performed in 2D axisymmetric conditions, using COMSOL Multiphysics software.

Figure 10 shows the maps of current density together with current lines, the dissipated Joule power and the temperature when the sample temperature is around $700{ }^{\circ} \mathrm{C}(600 \mathrm{~s})$. Table 2 shows, for the three configurations, the fraction of the current which passes through the sample and the comparison of the production of heat by the Joule effect in the sample with the heat flows exchanged by conduction, for the punches and the die, respectively.
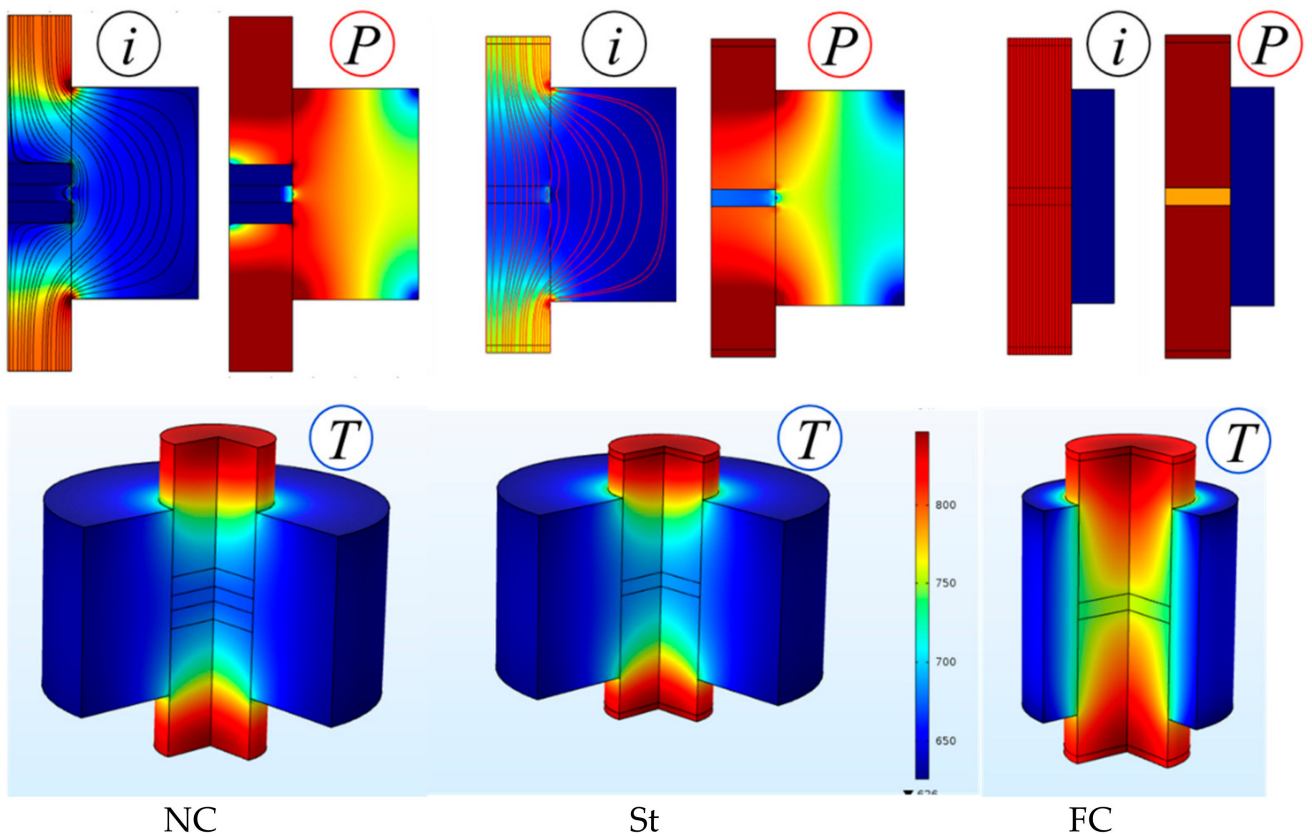

Figure 10. FEM simulation of heating for the three configurations. Snapshots of current density $(i)$, heat production rate $(P)$ (logarithmic scale) and temperature $(T)$ at $t=600 \mathrm{~s}$ (average $T$ around $700{ }^{\circ} \mathrm{C}$ inside the specimen). The same temperature-color scale is used for the three configurations in each case. 
Table 2. Calculated values of ratios of current and heat exchanges to Joule heating inside the specimen for the different configurations at $t=600 \mathrm{~s}$ (average $T$ around $700{ }^{\circ} \mathrm{C}$ inside the specimen). These ratios do not strongly evolve with time during heating.

\begin{tabular}{ccc}
\hline Configuration & Standard SPS & Fo Current \\
(St) & & 130 \\
\hline$\frac{\text { Current through sample }}{\text { Total current intensity }}$ & 410 & -110 \\
\hline$\frac{\text { Punches to sample heat flow }}{\text { Joule power inside sample }}$ & -360 & -1000 \\
\hline$\frac{\text { Die to sample heat flow }}{\text { Joule power inside sample }}$ & $28 \%$ & 1250 \\
\hline
\end{tabular}

A high fraction of the current passes through the sample in the standard configuration $(30 \%)$ and, of course, in the FC configuration (100\%). A small part of the current passes through the edges of the sample even in the NC configuration, due to the very high conductivity of the powder compared to that of graphite, but it remains very small (1\%).

Power dissipation (density of heat production) is highest at the punches and negligible in the sample in all cases (log representation in the figure). The local contribution of the Joule effect in the sample is, in any case, negligible for these copper samples.

In all cases, the punches-to-sample heat flow is considerably larger than the Joule power inside sample. Consequently, the sample is mainly heated by the punches.

The sample is cooled (negative flow) by the die, which is itself cooled by the external exchanges, as this flow is very large compared to the production of heat in the sample.

\subsection{Simulations vs. Experimental Results}

Figure 11 shows the calculated evolution of the temperature deviations between the thermocouple positions and the mean temperature of the samples. The sample was colder than the thermocouple in position A (located in the punch, considered as a heating source) and hotter than the thermocouple in position B (located in the die, considered as a cooling source). The simulations did not support these experimental results well. Indeed, the densification was greater and occurred earlier when the thermocouple was in position A. This suggested an underestimation of the sample temperature regarding location B.

There was no significant temperature difference between the configurations for the same thermocouple location (FC and STA on the one hand, NC and STB on the other hand). The experimental observation that only the absence of current (NC) led to a significant decrease in densification can therefore not be linked to a thermal cause. This suggests that the flow of a current in the sample modifies the densification mechanisms in this copper powder, for the given conditions. This effect appears to be a "threshold" effect because switching to $100 \%$ of the current (FC configuration) did not produce an effect significantly different from $30 \%$ of the current (St configuration). No modification of the microstructure by the flow of current could be observed to indicate the nature of this effect. 


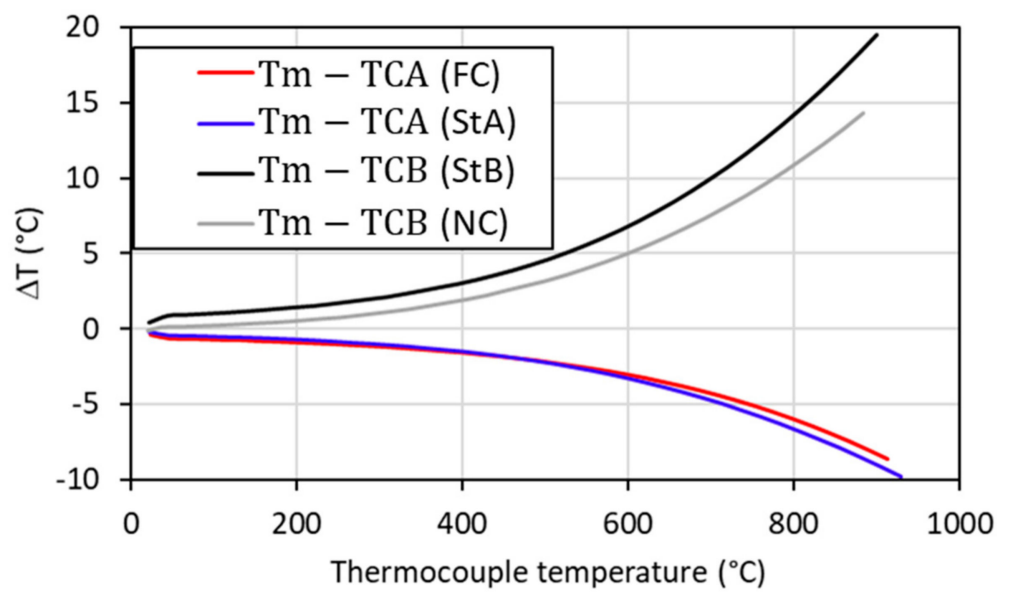

Figure 11. FEM simulation of heating for the three configurations. Evolution of the difference between the mean sample temperature $(\mathrm{Tm})$ and the temperature at the thermocouple position (A or B) during the simulated heating at about $50{ }^{\circ} \mathrm{C} \cdot \mathrm{min}^{-1}$.

\section{Conclusions}

The densification curves of a pure copper powder were analyzed for three different configurations and with different thermocouple positions, from the relative electrical conductivities of the sample and the tool, from FEM simulations and from SEM observations of fracture surfaces. Densification appeared to be sensitive to the position of the regulation thermocouple. This could be explained by different actual thermal cycles applied to the samples, due to thermal gradients inside the system. Only the absence of current in the specimen led to a decrease in densification. The effective conductivity of the copper sample was more than 25 times higher than that of the graphite tool. Therefore, copper specimens were scarcely heated by the tool. However, FEM simulations highlighted no significant temperature differences between the configurations, suggesting that this was not linked to a thermal cause but rather to a current effect. However, no modification of the microstructure by the flow of current could be observed.

Author Contributions: Conceptualization, S.L.G., J.-M.C. and F.B.; methodology, R.C.; validation, J.-M.C., S.L., S.L.G. and F.B.; formal analysis, R.C. and F.C.; investigation, R.C., S.L.G. and S.L.; resources, R.C., S.L. and F.C.; writing—original draft preparation, R.C. and S.L.G.; writing—review and editing, J.-M.C. and S.L.G.; supervision, J.-M.C. and F.B. All authors have read and agreed to the published version of the manuscript.

Funding: This work received a grant from the French National Agency (ANR) (ANR-11-BS09-020-02MF2) as part of the project MF2.

Data Availability Statement: Data is contained within the article. A part of data presented in this study are available in [Collet. $R$ Thèse de doctorat "Mécanismes de consolidation et de densification de poudres de cuivre lors d'un frittage par SPS", Université de bourgogne, 30 novembre 2015].

Acknowledgments: The authors thank Frédéric Herbst (ICB, UMR 6303 CNRS) for his help with the SEM analyses.

Conflicts of Interest: The authors declare no conflict of interest.

\section{References}

1. Tokita, M. Trends in advance SPS Spark Plasma Sintering systems and technology. J. Soc. Powder Technol. Jpn. 1993, 30, 790-804. [CrossRef]

2. Song, X.; Liu, X.; Zhang, J. Neck Formation and Self-Adjusting Mechanism of Neck Growth of Conducting Powders in Spark Plasma Sintering. J. Am. Ceram. Soc. 2006, 89, 494-500. [CrossRef]

3. Diouf, S.; Fedrizzi, A.; Molinari, A. A fractographic and microstructural analysis of the neck regions of coarse copper particles consolidated by spark plasma sintering. Mater. Lett. 2013, 111, 17-19. [CrossRef] 
4. Zhang, Z.H.; Liu, Z.F.; Lu, J.F.; Shen, X.B.; Wang, F.C.; Wang, Y.D. The sintering mechanism in spark plasma sintering-Proof of the occurrence of spark discharge. Scripta Mater. 2014, 81, 56-59. [CrossRef]

5. Aman, Y.; Garnier, V.; Djurado, E. Pressure-less spark plasma sintering effect on non-conventional necking process during the initial stage of sintering of copper and alumina. J. Mater. Sci. 2012, 47, 5766-5773. [CrossRef]

6. Guyot, P.; Rat, V.; Coudert, J.F.; Jay, F.; Maître, A.; Pradeilles, N. Does the Branly effect occur in spark plasma sintering? J. Phys. D Appl. Phys. 2012, 45, 092001. Available online: https://iopscience.iop.org/article/10.1088/0022-3727/45/9/092001 (accessed on 1 November 2021). [CrossRef]

7. Ratzker, B.; Sokol, M.; Kalabukhov, S.; Frage, N. Compression creep of copper under electric current studied by a spark plasma sintering (SPS) apparatus. Mater. Sci. Eng. A. 2018, 712, 424-429. [CrossRef]

8. Collet, R.; Le Gallet, S.; Charlot, F.; Lay, S.; Chaix, J.M.; Bernard, F. Oxide reduction effects in SPS processing of Cu atomized powder containing oxide inclusions. Mater. Chem. Phys. 2016, 173, 498-507. [CrossRef]

9. Hulbert, D.M.; Anders, A.; Andersson, J.; Lavernia, E.J.; Mukherjee, A.K. A discussion on the absence of plasma in spark plasma sintering. Scr. Mater. 2009, 60, 835-838. [CrossRef]

10. Demuynck, M.; Erauw, J.P.; Van der Biest, O.; Delannay, F.; Cambier, F. Densification of alumina by SPS and HP: A comparative study. J. Eur. Ceram. Soc. 2012, 32, 1957-1964. [CrossRef]

11. Medri, V.; Monteverde, F.; Balbo, A.; Bellosi, A. Comparison of $\mathrm{ZrB}_{2}-\mathrm{ZrC}-\mathrm{SiC}$ Composites Fabricated by Spark Plasma Sintering and Hot-Pressing. Adv. Eng. Mater. 2005, 7, 159-163. [CrossRef]

12. Bernard-Granger, G.; Addad, A.; Fantozzi, G.; Bonnefont, G.; Guizard, C.; Vernat, D. Spark plasma sintering of a commercially available granulated zirconia powder: Comparison with hot-pressing. Acta Mater. 2010, 58, 3390-3399. [CrossRef]

13. Lee, G.; Olevsky, E.A.; Maniere, C.; Maximenko, A.; Izhvanov, O.; Back, C.; McKittrick, J. Effect of electric current on densification behavior of conductive ceramic powders consolidated by spark plasma sintering. Acta Mater. 2018, 144, 524-533. [CrossRef]

14. Balbo, A.; Sciti, D. Spark plasma sintering and hot pressing of $\mathrm{ZrB}_{2}-\mathrm{MoSi}_{2}$ ultra-high-temperature ceramics. Mater. Sci. Eng. A. 2008, 475, 108-112. [CrossRef]

15. Langer, J.; Hoffmann, M.J.; Guillon, O. Direct comparison between hot pressing and electric field-assisted sintering of submicron alumina. Acta Mater. 2009, 57, 5454-5465. [CrossRef]

16. Trzaska, Z.; Bonnefont, G.; Fantozzi, G.; Monchoux, J.P. Comparison of densification kinetics of a TiAl powder by spark plasma sintering and hot pressing. Acta Mater. 2017, 135, 1-13. [CrossRef]

17. Collet, R.; Le Gallet, S.; Lay, S.; Charlot, F.; Bonnefont, G.; Fantozzi, G.; Chaix, J.M.; Bernard, F. SPS Mechanisms in Spherical Copper Powders. In Proceedings of the Congress Proceedings from World PM2016 Congress \& Exhibition, Hamburg, Germany, 9-13 October 2016.

18. Saunders, T.; Grasso, S.; Reece, M.J. Plasma formation during electric discharge ( $50 \mathrm{~V})$ through conductive powder compacts. J. Eur. Ceram. Soc. 2015, 35, 871-877. [CrossRef]

19. Chaim, R. Densification mechanisms in spark plasma sintering of nanocrystalline ceramics. Mater. Sci. Eng. A. 2007, 443, 25-32. [CrossRef]

20. Munir, Z.A.; Anselmi-Tamburini, U.; Ohyanagi, M. The effect of electric field and pressure on the synthesis and consolidation of materials: A review of the spark plasma sintering method. J. Mater. Sci. 2006, 41, 763-777. [CrossRef]

21. Collet, R.; Le Gallet, S.; Naimi, F.; Charlot, F.; Bonnefont, G.; Fantozzi, G.; Chaix, J.M.; Bernard, F. Effect of current on the sintering of pre-oxidized copper powders by SPS. J. Alloys Compd. 2017, 692, 478-484. [CrossRef]

22. Collard, C.; Trzaska, Z.; Durand, L.; Chaix, J.M.; Monchoux, J.P. Theoretical and Experimental Investigations of Local Overheating at Particle Contacts in Spark Plasma Sintering. Powder Technol. 2017, 321, 458-470. [CrossRef]

23. Anselmi-Tamburini, U.; Gennari, S.; Garay, J.E.; Munir, Z.A. Fundamental investigations on the spark plasma sintering/synthesis process: II. Modeling of current and temperature distributions. Mater. Sci. Eng. A 2005, 394, 139-148. [CrossRef]

24. Trapp, J.; Kieback, B. Fundamental principles of spark plasma sintering of metals: Part I-Joule heating controlled by the evolution of powder resistivity and local current densities. Powder Metall. 2019, 62, 297-306. [CrossRef]

25. Minier, L.; Le Gallet, S.; Grin, Y.; Bernard, F. Influence of the current flow on the SPS sintering of a Ni powder. J. Alloys Compd. 2010, 508, 412-418. [CrossRef]

26. Bruggemann, D.A.G. Calculation of Effective Constitutive Parameters of Heterogeneous Substances, I, Permittivity and Conductivity for Dilute Composite Mediums of Isotropic Substances. Ann. Phys. 1935, 24, 636-679.

27. Argento, C.; Bouvard, D. Modeling the effective thermal conductivity of random packing of spheres through densification. Lnt. J. Heat Mass Transfer. 1996, 39, 1343-1350. [CrossRef]

28. Lide, D.R. CRC Handbook of Chemistry and Physics, 64th ed.; Lide, D.R., Ed.; CRC Press: Boca Raton, FL, USA, 2004. 